\title{
An Evaluation of the Organ Dose Received by Cardiologists Arising From Angiography Examinations in Educational Hospital in Rasht
}

\author{
Akram Shoshtary ${ }^{1}$, Jalil Pirayesh Islamian ${ }^{1}$, Mohsen Asadinezhad $^{2} \&$ Alireza Sadremomtaz ${ }^{3}$ \\ ${ }^{1}$ Department of Medical Physics, Faculty of Medicine, Tabriz University of Medical Sciences, Tabriz, Iran \\ ${ }^{2}$ Department of Biophysics and Biochemistry, Faculty of Medicine, Guilan University of Medical Sciences, \\ Guilan, Iran \\ ${ }^{3}$ Department of physics, Guilan University, Guilan, Iran \\ Correspondence: Jalil Pirayesh Islamian, BSC., MSc., Ph.D., Department of Medical radiation Science, Faculty \\ of Medicine, Tabriz University of Medical Sciences, Attar Nayshapouri St, Azadi Ave, 5166614766,Tabriz, Iran. \\ Tel \& Fax: 98-413-336-4660; Cell: 98-910-400-4435. E-mail: pirayeshj@gmail.com, pirayeshj@tbzmed.ac.ir
}

Received: September 21, 2015 Accepted: November 1, 2015 Online Published: November 18, 2015

doi:10.5539/gjhs.v8n7p185 URL: http://dx.doi.org/10.5539/gjhs.v8n7p185

\begin{abstract}
Interventional procedures, cine acquisitions and operation of fluoroscopic equipment in high-dose fluoroscopic modes, involve long fluoroscopic times which can lead to high staff doses. Also, Coronary angiography (CA) procedures require the cardiologist and assisting personnel to remain close to the patient, which is the main source of scattered radiation. Thus, radiation exposure is a significant concern for radiation workers and it is important to measure the radiation doses received by personnel and evaluate the parameters concerning total radiation burden. In this research, we investigated radiation doses to 10 cardiologists performing $120 \mathrm{CA}$ procedures. Using thermo luminescent dosimeters doses to the wrists, thyroid and eyes per procedure were measured. Based on the measured dose values, maximum doses to the Left wrist, Right wrist, thyroid and eyes of cardiologist were measured $241.45 \mu \mathrm{Sv}, 203.17 \mu \mathrm{Sv}, 78.21 \mu \mathrm{Sv}$ and $44.58 \mu \mathrm{Sv}$, respectively. The results of this study indicate that distance from the source, use of protective equipment's, procedure complexity, equipment performance, and cardiologist experience are the principal exposure-determining variables. It can be conclude that if adequate radiation protection approaches have been implemented, occupational dose levels to cardiologists would be within the regulated acceptable dose limits.
\end{abstract}

Keywords: coronary angiography, radiation dose, radiation worker, thermo luminescent dosimeter

\section{Introduction}

Interventional cardiology(IC) is a branch of cardiology where $\mathrm{x}$ - ray guided procedures are performed to diagnose and treat various heart disease which become recently leading the main cause of death (Domienik et al., 2012). IC procedures are performed in ever increasing numbers around the world (Durán et al., 2013). The main reason is that IC permits specialists to avoid complicated invasive surgery, which some patients might not tolerate because of factors such as patient's age or pathology, and this results in a reduced length of hospital stay in comparison with coronary artery bypass grafting (Baim \& Grossman, 1994).

Coronary angiography (CA) is defined as the coronary vessels radiographic visualization after direct opacification with contrast media. It is most commonly used to determine the coronary anatomy, the presence and extent of obstructive coronary artery disease (CAD) and to assess the feasibility and appropriateness of various therapy forms such as revascularization by percutaneous or surgical interventions. Despite the advances in other diagnostic methods, it is still "the golden standard" of coronary disease diagnostics (Caluk, 2011).

$\mathrm{CA}$ is a complex combination of relatively low dose screening (fluoroscopy mode; fluoro) and relatively high dose rapid sequence of radiographic exposures recorded in a film (cineradiography mode; cine).

Radiation dose is an unintended consequence of some diagnostic and interventional procedures (Mercuri et al., 2008). Thus, proper dose assessment is a prerequisite for its management. Although interventional cardiac examinations account for $12 \%$ of all radiological procedures, they are responsible for delivering the highest radiation dose (up to $50 \%$ of the total collective effective dose) (Sun et al., 2013). 
Cardiologists encounter much more radiation than most other medical staff due to their working position being close to the beam and the patient (the source of scatter radiation). Therefore, radiation exposure is a significant concern for interventional cardiologists due to the increasing workloads and the procedures complexity over the last decade (Sun et al., 2013).

Dr. Heshmat hospital in Rasht - Iran is one of the important therapeutic centers, where cardiology department accepts many patients for cardiac diagnostic and therapeutic study. On average, about $3600 \mathrm{CA}$ tests are performed annually in this center.

This present survey was focused on estimating cardiologist doses for different anatomical location during CA procedures by thermo luminescent dosimeter (TLD), as the most widely used technology for personal dosimetry (Foti et al., 2008).

\section{Methods and Materials}

All interventional procedures were performed in the catheterization department of the Dr. Heshmat university hospital of Rasht, which equipped with a variety of radiation protection equipment, including: Personal protective equipment (apron, thyroid collar, lead glasses) and room protective equipment (protective drapes suspended from the table and from the ceiling).The IC examinations were performing using a SIMENS system (Axiom Artis dfc model, Germany) with an under couch tube. This system's features are listed in Table 1:

Table 1. Imaging system features

\begin{tabular}{ll}
\hline Field size $\left(\mathrm{cm}^{2}\right)$ & $13,17,21,23\left(\mathrm{~cm}^{2}\right)$ \\
\hline Frame Rate(F/Sec) & $10,15(\mathrm{~F} / \mathrm{Sec})$ \\
Fluoro(kVp) & $30-80(\mathrm{kVp})$ \\
Fluoro $(\mathrm{mA})$ & $4-15(\mathrm{~mA})$ \\
Cine $(\mathrm{kVp})$ & $120(\mathrm{kVp})$ \\
Cine $(\mathrm{mA})$ & $30-170(\mathrm{~mA})$ \\
\hline
\end{tabular}

Field size $=$ radiation field.

The total filtration was automatically varied depending on the selected imaging mode having values between 2 and $3.5 \mathrm{~mm} \mathrm{Al}$, and tube setting such as peak voltage and tube current were controlled by the automatic exposure control (AEC).

To verify the timer and tube voltage, Diavolt (PTW-Freiburg), made in Germany, were used. To perform the test, dosimeter was located at the interventional reference point. No differences has been spotted between angiography system timer and dosimetery system. The difference in voltage was less than $3 \%$.

Procedures were performed by residents, visiting cardiologists and trainees.

Table 2. Cardiologists demographic data

\begin{tabular}{lllllll}
\hline & Sex & $\begin{array}{l}\text { Age } \\
(\text { Year })\end{array}$ & $\begin{array}{l}\text { Height } \\
(\mathrm{Cm})\end{array}$ & $\begin{array}{l}\text { Weight } \\
(\mathrm{Kg})\end{array}$ & $\begin{array}{l}\text { Experience } \\
(\text { Year })\end{array}$ & Specific disease \\
\hline C1 & M & 42 & 181 & 103 & 5 & No \\
C2 & M & 39 & 179 & 83 & 4 & No \\
C3 & F & 45 & 173 & 95 & 4 & No \\
C4 & F & 49 & 159 & 72 & 4 & No \\
C5 & M & 30 & 165 & 79 & 3 & No \\
C6 & M & 37 & 172 & 87 & 2 & No \\
C7 & M & 36 & 184 & 68 & 3 & No \\
C8 & F & 39 & 176 & 70 & 2 & No \\
C9 & F & 35 & 165 & 91 & 2 & No \\
C10 & M & 33 & 157 & 84 & 3 & No \\
\hline
\end{tabular}

F: Female; M: Male. 
From June 2014 to December 2014, the samples were randomly selected, including male and female patients undergoing CAG without any optional criteria. Patient's demographic data (height, age and weight) are mentioned in Table 3 . The total number of the patients were 76 male and 44 female ones.

Table 3. Patient demographic data

\begin{tabular}{llll}
\hline & Height[cm] & weight[kg] & age[years] \\
\hline Average & 157.6 & 76.90 & 58 \\
Maximum & 178 & 118 & 69 \\
Minimum & 132 & 54 & 47 \\
\hline
\end{tabular}

Dose measurements were performed using thermoluminescent dosimetetrs (TLDs) LiF crystals, doped with magnesium, copper and phosphorus (LiF:Mg,Cu, P). Formerly, the annealed TLDs, in a Harshaw 3500 TLD reader at temperature of $240 \mathrm{C}$ for 10 minutes, were calibrated at the secondary Standard Dosimetry Laboratory (SSDL), by giving them a certain dose of radiation. The calibration was performed with the calibration detectors in a plexi holder and irradiated with a Cs- 137 source (with $0.667 \mathrm{MeV}$ gamma rays).

Dosimeters were stuck at six positions during the procedure. The dose received by 10 cardiologists in a single examination was determined by placing thermoluminescent dosimeters in the selected points on the body where apparently higher doses are expected.

Ten Background TLDs were kept for every measurement and the background signal was subtracted from the measured thermoluminescence signals. Every TLD-reading was also corrected for the individual sensitivity of the respective TLD.

While performing the examinations, all the physicians included in the study were wearing lead aprons, thyroid collars, and protective glasses equivalent to $0.5 \mathrm{~mm}$ lead. Also, lead glass screens and above and below table shield were used. For each examination, we recorded the measurement protocol. The protocol included the information on the working procedure and the protective measures used, the position of the cardiologist with respect to the X-ray beam, complexity of the procedure, accessing the catheter, the operator's experience, the radiation field parameters; i.e. tube voltage; DAP value; fluoroscopy time.

The mean fluoroscopy time, the number of procedure and image and mean DAP for patients subjected to CA are presented in Table 4.

Table 4. Dosimetric parameters for monitored procedures

\begin{tabular}{llll}
\hline Physician & Number of procedure & Mean fluoroscopy time \pm SD $(\mathrm{min})$ & Mean DAP $\pm \mathrm{SD}\left(\mu \mathrm{Gy} \cdot \mathrm{m}^{2}\right)$ \\
\hline $\mathrm{C} 1$ & 12 & $5.57 \pm 1.19$ & $2085.56 \pm 1210.05$ \\
$\mathrm{C} 2$ & 12 & $2.74 \pm 1.97$ & $2055.07 \pm 921.50$ \\
$\mathrm{C} 3$ & 12 & $3.22 \pm 3.25$ & $2389.24 \pm 1336.76$ \\
$\mathrm{C} 4$ & 12 & $2.75 \pm 1.03$ & $2349.53 \pm 801.97$ \\
$\mathrm{C} 5$ & 12 & $3.08 \pm 2.81$ & $2469.08 \pm 739.74$ \\
C6 & 12 & $3.26 \pm 1.93$ & $2856.83 \pm 1646.26$ \\
C7 & 12 & $3.24 \pm 2.31$ & $2377.75 \pm 1147.88$ \\
C8 & 12 & $3.32 \pm 2.07$ & $2791.96 \pm 1403.13$ \\
C9 & 12 & $4.54 \pm 5.01$ & $2953.91 \pm 1540.0$ \\
C10 & 12 & $4.30 \pm 506$ & $2638.4 \pm 1544.14$ \\
\hline
\end{tabular}

The TLDs were placed inside thin plastic bags to be protected from the physical and chemical damage, and taped on the parts of the body were to be monitored. In brief, 6 TLD were used for each test (right and left wrist on the palmar side, under and outside thyroid shield, and under and over the lead glasses). The measurement protocol was common for all procedures so that all results are homogenized and can be analyzed and compared. The 
TLDs were always read $24 \mathrm{~h}$ after irradiation using a Harshaw 3500 TLD reader. The dose per procedure to the wrists, thyroid and eyes was reported in units of $\mu \mathrm{Sv}$.

Finally, the dose reduction (\%) of thyroid and eye was determined by the following equation:

Organ dose reduction $(\%)=\frac{\text { over the shield dose-under the shield dose }}{\text { over the shield dose }} \times 100$

The data are summarized and reported with Meam, SD, Min and Max dose indicators. Also the data were analyzed using one- way ANOVA and SPSS22 software. The significance level was considered $\mathrm{p}<0.05$.

\section{Results}

Figure 1 shows the results on the average dose in each right and left wrists of 10 cardiologists.

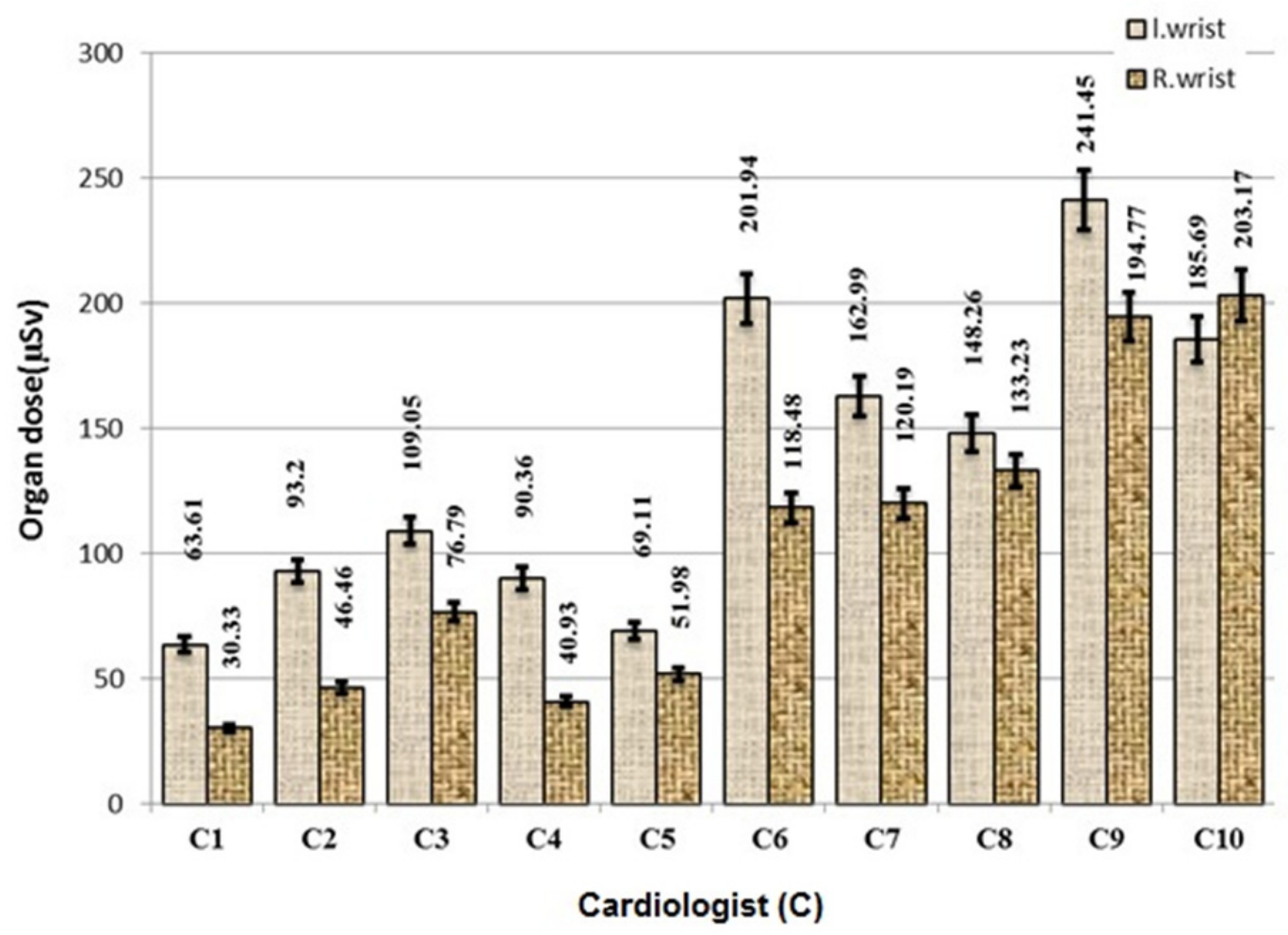

Figure 1. The average dose in each right and left wrists of 10 cardiologists (C1-C10) from interventional cardiology examinations

Depending on the type of procedure and the technique used, the operator dose per procedure, obtained from 63.61 to $241.45 \mu \mathrm{Sv}$ at the Left wrist and 30.33 to 203.17 at the Right wrist, and highest doses are concerned to 9 th cardiologist's Left wrist and $10^{\text {th }}$ cardiologist's Right wrist.

It was also observed that for most cardiologists, the Left wrist dose was more than Right one because of proximity to the tube. No significant differences was observed in dose value of Left and Right wrist of $\mathrm{C} 1-\mathrm{C} 5$ cardiologists.

The measured thyroid and eyes dose of 10 cardiologists per procedure from CA examinations is shown in Figure 2.

According to the obtained data, presented in Figure 2, the maximum thyroid and eye doses were found $78.21 \mu \mathrm{Sv}$ and $44.58 \mu \mathrm{Sv}$, respectively that were related to $9^{\text {th }}$ cardiologist (C9). Table 5 points out the summary of cardiologists' data for CA procedures in the present study. 


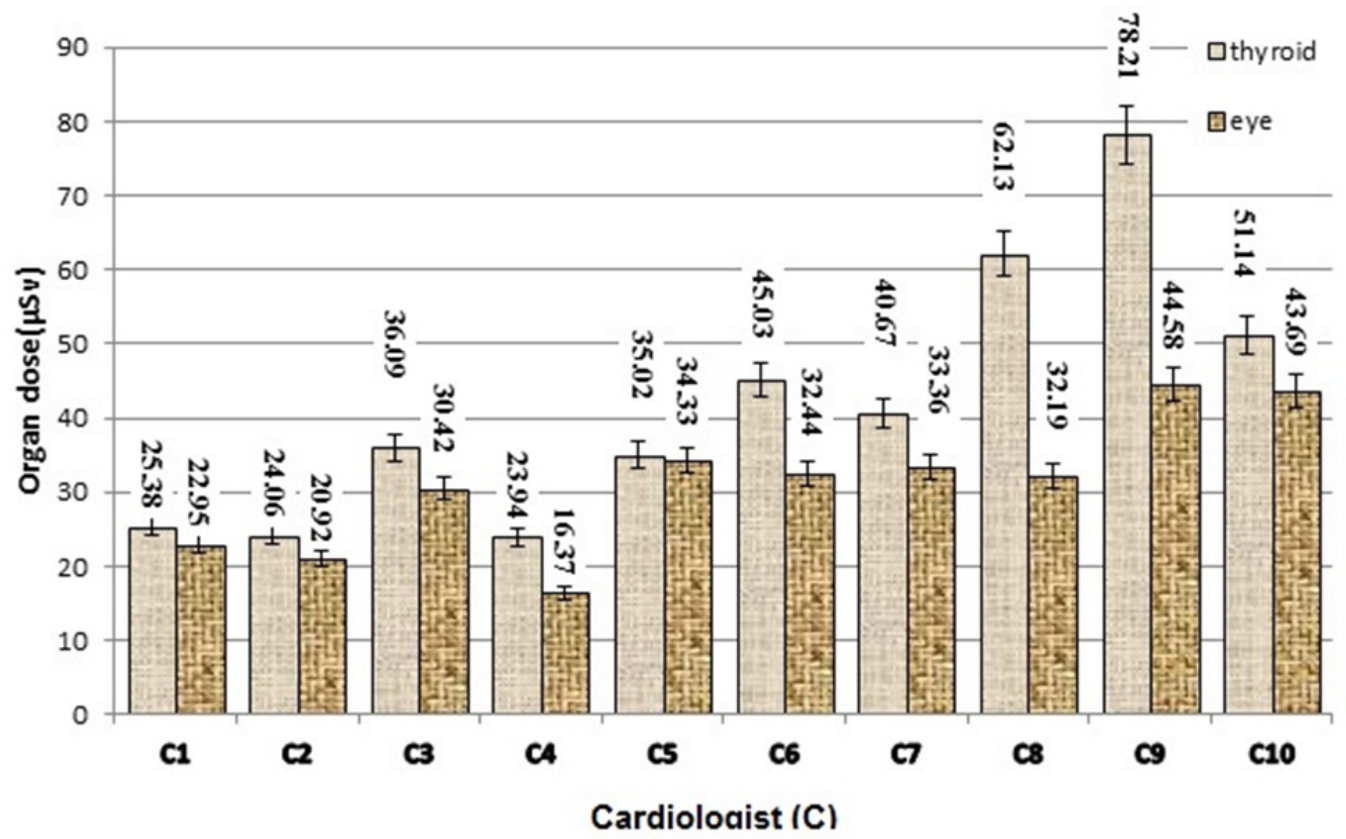

Figure 2. The measured thyroid and eyes dose of 10 cardiologists (C1-C10) per procedure from interventional cardiology examinations

Table 5. Summary of cardiologists' data for CA procedures in the present study

\begin{tabular}{llllll}
\hline Organ & Mean & S.D & Med & Min & Max \\
\hline Left wrist & 130.9 & 88.83 & 106.94 & 30.55 & 376.01 \\
Right wrist & 93.65 & 82.01 & 57.21 & 19.72 & 385.91 \\
Thyroid & 40.05 & 21.65 & 32.36 & 11.04 & 101.00 \\
Eye & 30.15 & 15.01 & 26.67 & 10.16 & 95.01 \\
\hline
\end{tabular}

Table 6 shows organ dose reduction when using protective shields.

Table 6. Thyroid and eye dose reduction (\%)

\begin{tabular}{lll}
\hline & Thyroid dose reduction (\%) & Eye dose reduction (\%) \\
\hline C1 & 36 & 34 \\
C2 & 35 & 35 \\
C3 & 27 & 27 \\
C4 & 38 & 34 \\
C5 & 33 & 26 \\
C6 & 39 & 37 \\
C7 & 53 & 38 \\
C8 & 28 & 25 \\
C9 & 41 & 24 \\
C10 & 41 & 30 \\
\hline
\end{tabular}

\section{Discussion}

For CA examinations, the obtained results have been analyzed statistically and no significant differences has was 
seen between the results at the confidence level $95 \%$.

The present results show an ample range of variation in doses at the locations monitored on the physicians, especially at their wrists, confirming the influence of equipment features, the complexity of the procedure, fluoroscopy time, work technique, shielding, and perhaps the most important of all, the cardiologist's experience. Some of the factors influence the dose to cardiologists, are listed in Table 7.

Table 7. Some of the factors affecting cardiologists dose in CA.

\begin{tabular}{ll}
\hline Category & Clinical problem, lesion characteristic, body habitus \\
\hline Patient & $\begin{array}{l}\text { Body size and height, experience and skill, work load, procedural technique, position with } \\
\text { respect to patient }\end{array}$ \\
Physician & Equipment- mounted shielding and personal protective shields \\
Shielding & \\
Angiographic equipment &
\end{tabular}

Examination time is an important factor, which related to experience and skill of cardiologists, but no meaningful correlation was found between the examination time and dose to cardiologist.

The mean DAP values of this survey for CA procedures are comparable with mean DAP from other studies.

Table 8. Comparison of this study with literature in CA

\begin{tabular}{ll}
\hline & Mean DAP value $\left[\mathrm{Gy}^{\mathrm{cm}}{ }^{2}\right]$ \\
\hline Vañó et al (1995) & 66.5 \\
Padovani et al (1998) & 55.9 \\
Van de putte et al (2000) & 60.6 \\
Karambatsakidou et al (2005) & 49.0 \\
This study & 25.23 \\
\hline
\end{tabular}

As illustrated in Table 2, mean DAP in the present research is less than other studies.

This variations in DAP values for similar procedures could arise from changes in field size, cine and fluoroscopic time, physician experience and skill and the complexity of cases.

There is a great difficulty in comparing the dosimetric results in the various studies because many different factors influence the cardiologist's doses. Generally, the factors influencing the dose were grouped in: the factors related to the patients (age, sex, weight, etc.), the ones related to the equipment and the factors related to cardiologist (technique, screening time, number of procedures, type of the procedures, the operator's skill, the training level in radiation protection, etc.) (Jokic et al., 2011). Table 9 presents a comparison of our data with the similar studies:

Table 9. The data on the organ dose (in $\mu \mathrm{Sv}$ ) of radiation workers for interventional cardiology in three studies

\begin{tabular}{llll}
\hline Organ & Present study (CA) & $\begin{array}{l}\text { Efstathopoulos et al (2011) } \\
\text { (IC) }\end{array}$ & $\begin{array}{l}\text { Zare et al (2007) } \\
\text { (CA) }\end{array}$ \\
\hline Left wrist & $63.61-241.45$ & $20-3684$ & $31.8-358.7$ \\
Right wrist & $30.33-203.17$ & $14-138$ & $12.0-124.0$ \\
Thyroid & $23.94-78.21$ & - & $1.2-100.3$ \\
Eyes & $16.37-44.58$ & $0-61$ & - \\
\hline
\end{tabular}

The present study showed significant variations in the levels of radiation dose received by cardiologists in 
different studies. The only study conducted in Mashhad by Zare et al (2007). Suggested the highest dose in right hand, left hand and thyroid 124, 358.7, $100.3 \mu \mathrm{Sv}$, respectively. Comparing the values obtained in current and previous research indicated that the maximum left wrist and thyroid dose in our study was lower, while the maximum right wrist dose was higher.

As mentioned before, some of the factors responsible for dose variability are the complexity of the procedure, operator's experience, training level in radiation protection, and type and performance of $\mathrm{x}$-ray equipment available in the catheterization laboratory (Pantos et al., 2009). Our study also indicate the effectiveness of the related parameters on the dose.

Of all CA laboratory personnel, the performing physician is subject to the highest radiation dose, and numerous patients, physician and shielding factors influence the cardiologist's dose to different degrees.

Chida et al (2013) compared the annual occupational dose among interventional radiology staff. The annual occupational doses of physicians, nurses, and radiologic technologists were recorded. They found that the annual occupational dose for interventional radiology staff was in the order of physicians $>$ nurses $>$ radiologic technologists. This is readily explained by the relative proximity of the cardiologist to the patient and the $\mathrm{x}$-ray beam. Also, Kim and Miller (2009), reported that decreasing the distance from $1 \mathrm{~m}$ to $0.75 \mathrm{~m}$ doubles the occupational radiation dose.

An interesting study was performed by Silva et al (2011) evaluating the values of radiation doses received by physician during IC procedures. The mean effective dose per procedure for physician was $11 \mu \mathrm{Sv}$, and the highest mean equivalent doses were 382 in the left hand and $150 \mu \mathrm{Sv}$ in the left eye.

Another study was performed by Vano et al., (2006) that evaluated the cardiologist's occupational doses for a period of 15 years (1989 to 2004). The mean values in $\mathrm{mSv} /$ year decreased from 11.6(1989-1992) to 1.6(1993-1998) and to 1.2(1999-2004).

Efstathopoulos et al (2011), attempted to estimate occupational doses to the extremities and the eyes for interventionists and the assisting laboratory nurse in interventional procedures. For the physicians, the parts of the body that received the highest doses were found at the left wrist, and the annual limits eyes and extremities are not exceeded even for the busiest physicians. Our study also confirmed the results obtained by Efstathopoulos et al (2011).

Unlike their study, we investigated the effect of shielding on dose, which results presented in Table 6.

Dendy (2008) suggested that doses to hands are highly dependent on their position relative to the beam and different hand movements in different procedures.

Domienik et al (2012), analyzed the dose distributions at the region of eye lens and extremities in IC procedures with TL dosimeters (MCP-N). The main objective was to obtain the typical locations of highest doses and to estimate the dose ranges for the selected types of procedures with regard to the following parameters: the X-ray tube geometry, the presence of additional protective equipment and staff position (related to the access). They found that even for the same type of procedure, the variation in the dose levels might be significant depending on the above-mentioned parameters. Therefore, they concluded that the eye dosimeter should be placed aside the eye which is nearest to the X-ray tube. Another study also visualised the dose distribution inside the head, both when protective eyewear were used and without such protection, and they proved that positioning the dosimeter at the eyebrow could lead to an underestimation of the lens dose of as much as $45 \%$ (Geber et al., 2011).

Comparison of these findings, the best position for monitoring of eye doses, we found to be at the side of the head nearest to the radiation source, to avoid eyes dose underestimation.

There are a large number of influencing factors that can give a significant variability for the eye doses: different geometries of the various X-ray systems, protective equipment, the complexity of the CA procedures (fluoroscopy time, number of acquired images), work technique (X-ray tube configuration, projections used, etc.) and physician's experience. In this study, cardiologist C9 has a longer fluoroscopic time and higher DAP value with a slow working behavior, compared to the others. This difference is largely due to his less experience. So it is particularly important that cardiologists are trained in clinical technique and radiation protection.

The eye dose results for the cardiologists collated in this survey show that the operator's position and body height have major impact on the amount of radiation doses to different parts of the body. As expected, tall cardiologists receive a lower eye dose than a short cardiologists since the distances from the eyes to patient entrance site can significantly vary depending upon the operator's height.

The results of this study indicated that radiation doses were higher on the left side of the operator's body 
(specially the left wrist), because the left side is closer to the X-ray beam when the cardiologist is standing at the patient's right side, but in the previous study was found that left hand receive the two- fold dose as compared with the right hand during cardiac catheterization (Kantonsspital, 2005). It is important to mention that the radiation dose to the personnel is directly related to the dose to the patient since the major contribution is scattered radiation from the patient (Axelsson, 2007). In addition, cardiologist's doses can considerably increase if inappropriate X-ray equipment or inadequate personal protection is used (Valentine, 2000).

Radiation shielding is one of the most efficient and easiest methods to protect the staff during interventional cardiology procedures (Todorovic et al., 2011). Fetterly et al., recommended that radiation shields must be thoughtfully placed and actively managed both before and during the procedure to be effective in providing substantial protection during IC procedures (Sun et al., 2013).

As shown in Table 9, there is substantial variation in doses observed for the same type of procedure, indicating that radiological protection practices can be improved. The results of the simulations that were performed by Koukorava et al., suggested that a lead glass (if properly worn) can reduce the doses to the eye lens by a factor 3 to 7 (Vanhavere et al., 2011). Combining various types of shielding (i.e., table-suspended drapes, ceiling-suspended screens, aprons, leaded glasses, mobile shields, and disposable drapes) results in a dramatic dose reduction for the operator (Miller et al., 2009).

It is proved that, leaded glasses decrease the dose to the operator's eye exposure by a factor of approximately five to 10 (Thornton et al., 2010). Garments, lead goggles, ceiling suspended shields, curtains under the table and other protective equipment provide a significant reduction in occupational doses (Vano, 2003). Of course, the amount of radiation attenuated by a material depends on the elemental composition of the material, its thickness and the energy of the radiation passing through (Francis et al., 2011). In our study, the protection by shielding was also considered by the staff and thus we haven't considered a comparison for the related doses.

\section{Conclusion}

The interventional cardiologists encounter much more radiation than most other medical staff due to their working position being close to the X-ray beam and the patient (the source of scatter radiation). The increased workload, the complexity of the interventional procedures, fluoroscopy time, and distance from the scattering area on the patient contribute significantly to the amount of radiation exposure to the cardiologists. Training of the operator in radiation protection methods may be a successful action to reduce occupational doses. In order to keep doses as low as applicable, evaluation and follow up of radiation doses received by the physicians should be considered an important part of quality assurance programs for interventional cardiology procedures, and protective devices must be used appropriately.

\section{Acknowledgements}

We express our gratitude to the head and all staff members of the catheterization department of Dr. Heshmat Hospital of Guilan University of Medical Sciences in Rasht for their sincere cooperation. We wish to have a special thanks to Behnaz Ghanbar Mogadam, medical physicist of Guilan university for her sincerely assistance in providing a proper study condition. This work was financially supported by the deputy of research in faculty of Medicine, Tabriz University of Medical Sciences, Tabriz, Iran (\# 54.25674).

\section{Conflict of Interest}

The authors declare that there is no conflict of interests regarding the publication of this paper.

\section{References}

Axelsson, B. (2007). Optimisation in fluoroscopy. Biomedical Imaging and Intervention Journal, 3(2). http://dx.doi.org/10.2349/biij.3.2.e47

Baim, D., Grossman, W. (1994). Cardiac catheterization, angiography, and intervention. Baltimore: Williams \& Wilkins.

Caluk J. (2011). Procedural Techniques of Coronary Angiography. In Advances in the Diagnosis of Coronary Atherosclerosis. European Union: InTech. http://dx.doi.org/10.5772/18612

Chida, K., Kaga, Y., Haga, Y., Kataoka, N., Kumasaka, E., Meguro, T., \& Zuguchi, M. (2013). Occupational Dose in Interventional Radiology Procedures. American Journal of Roentgenology, 200(1), 138-141. http://dx.doi.org/10.2214/AJR.11.8455

Dendy, P. P. (2008). Radiation risks in interventional radiology. The British Journal of Radiology, 81(961), 1-7. http://dx.doi.org/10.1259/bjr/15413265 
Domienik, J., Brodecki, M., \& Rusicka, D. (2012). A study of the dose distribution in the region of the eye lens and extremities for staff working in interventional cardiology. Radiation Measurements, 47(2), 130-138. http://dx.doi.org/10.1016/j.radmeas.2011.12.004

Durán, A., Hian, S. K., Miller, D. L., Le Heron, J., Padovani, R., \& Vano, E. (2013). Recommendations for occupational radiation protection in interventional cardiology. Catheterization and Cardiovascular Interventions, 82(1), 29-42. http://dx.doi.org/10.1002/ccd.24694

Efstathopoulos, E. P., Pantos, I., Andreou, M., Gkatzis, A., Carinou, E., Koukorava, C., ... Brountzos, E. (2011). Occupational radiation doses to the extremities and the eyes in interventional radiology and cardiology procedures. The British Journal of Radiology, 84(997), 70-77. http://dx.doi.org/10.1259/bjr/83222759

Foti, C., Padovani, R., Trianni, A., Bokou, C., Christofides, S., Corbett, R. H., ... Zdesar, U. (2008). Staff dosimetry in interventional cardiology: survey on methods and level of exposure. Radiation Protection Dosimetry, 129(1-3), 100-103. http://dx.doi.org/10.1093/rpd/ncn038

Francis, V., Abbas, A., Eleni, S., Francois, B., \& Jean-Francois, S. (2011). Protection of the Patient and the Staff from Radiation Exposure During Fluoroscopy-Guided Procedures in Cardiology. Advances in the Diagnosis of Coronary Atherosclerosis. http://dx.doi.org/10.5772/22786

Geber, T., Gunnarsson, M., \& Mattsson, S. (2011). Eye lens dosimetry for interventional procedures - Relation between the absorbed dose to the lens and dose at measurement positions. Radiation Measurements, 46(11), 1248-1251. http://dx.doi.org/10.1016/j.radmeas.2011.07.028

Jokic, V. S., Djurovic, B., \& Lukac, S. (2011). Occupational hand doses in interventional radiology. IAEA, 32(49).

Kantonsspital, S. G. (2005). Radiation exposure and radiation protection in interventional cardiology. Kardiovaskuläre Medizin, 8(4), 124-132.

Karambatsakidou, A., Tornvall, P., Saleh, N., Chouliaras, T., Löfberg, P.-O., \& Fransson, A. (2005). Skin dose alarm levels in cardiac angiography procedures: is a single DAP value sufficient? The British Journal of Radiology, 78(933), 803-809. http://dx.doi.org/10.1259/bjr/14000648

Kim, K. P., \& Miller, D. L. (2009). Minimising radiation exposure to physicians performing fluoroscopically guided cardiac catheterisation procedures: A review. Radiation Protection Dosimetry, 133(4), 227-233. http://dx.doi.org/10.1093/rpd/ncp052

Mercuri, M., Moran, G., Gauthier, L., Sheth, T., Velianou, J., \& Natarajan, M. (2008). Radiation Dose in Interventional Cardiology Procedures: Urgent Need for Monitoring Dose and Establishing Diagnostic Reference Levels. Healthcare Quarterly, 11(1), 76-83. http://dx.doi.org/10.12927/hcq.2013.19501

Miller, D. L., Va-ó, E., Bartal, G., Balter, S., Dixon, R., Padovani, R., ... de Baère, T. (2009). Occupational Radiation Protection in Interventional Radiology: A Joint Guideline of the Cardiovascular and Interventional Radiology Society of Europe and the Society of Interventional Radiology. Cardiovasc Intervent Radiol, 33(2), 230-239. http://dx.doi.org/10.1007/s00270-009-9756-7

Padovani, R., Novario, R., \& Bernardi, G. (1998). Optimisation in Coronary Angiography and Percutaneous Transluminal Coronary Angioplasty. Radiation Protection Dosimetry, 80(1), 303-306. http://dx.doi.org/10.1093/oxfordjournals.rpd.a032531

Pantos, I., Patatoukas, G., Katritsis, D., \& Efstathopoulos, E. (2009). Patient Radiation Doses in Interventional Cardiology Procedures. Current Cardiology Reviews, $4(1), \quad 1-11$. http://dx.doi.org/10.2174/157340309787048059

Silva, M. do S. R. da, Khoury, H. J., Borrás, C., Oliveira, A. F., Vianna, H. F. de P., Oliveira, F. R. A. de, ... Mota, F. B. (2011). Dosimetria de pacientes e médicos em intervenções coronárias percutâneas em Recife, Pernambuco, Brasil. Radiol Bras, 44(2), 90-96. http://dx.doi.org/10.1590/S0100-39842011000200008

Sun, Z., AbAziz, A., \& Khairuddin Md Yusof, A. (2013). Radiation-Induced Noncancer Risks in Interventional Cardiology: Optimisation of Procedures and Staff and Patient Dose Reduction. BioMed Research International, 1-11. http://dx.doi.org/10.1155/2013/976962

Thornton, R. H., Dauer, L. T., Altamirano, J. P., Alvarado, K. J., St. Germain, J., \& Solomon, S. B. (2010). Comparing Strategies for Operator Eye Protection in the Interventional Radiology Suite. Journal of Vascular and Interventional Radiology, 21(11), 1703-1707. http://dx.doi.org/10.1016/j.jvir.2010.07.019

Todorovic, N., Bikit, I., Nikolov, J., Forkapic, S., Mrdja, D., \& Todorovic, S. (2011). Workplace Monitoring 
During Interventional Cardiology Procedures. World Acad Sci Eng Technol, 5(4), 374-6.

Valentin, J. (2000). Avoidance of radiation injuries from medical interventional procedures, ICRP Publication 85. Annals of the ICRP, 30(2), 51-57. http://dx.doi.org/10.1016/S0146-6453(01)00011-2

Van de Putte, S., Verhaegen, F., Taeymans, Y., \& Thierens, H. (2000). Correlation of patient skin doses in cardiac interventional radiology with dose-area product. The British Journal of Radiology, 73(869), 504-513. http://dx.doi.org/10.1259/bjr.73.869.10884747

Vanhavere, F., Carinou, E., Domienik, J., Donadille, L., Ginjaume, M., Gualdrini, G., ... Struelens, L. (2011). Measurements of eye lens doses in interventional radiology and cardiology: Final results of the ORAMED project. Radiation Measurements, 46(11), 1243-1247. http://dx.doi.org/10.1016/j.radmeas.2011.08.013

Vano, E. (2003). Radiation exposure to cardiologists: How it could be reduced. Heart, 89(10), 1123-1124. http://dx.doi.org/10.1136/heart.89.10.1123

Va-ó, E., González, L., Fernández, J. M., \& Guibelalde, E. (1995). Patient dose values in interventional radiology. BJR, 68(815), 1215-1220. http://dx.doi.org/10.1259/0007-1285-68-815-1215

Va-o, E., Gonzalez, L., Fernandez, J. M., Alfonso, F., \& Macaya, C. (2006). Occupational radiation doses in interventional cardiology: A 15-year follow-up. The British Journal of Radiology, 79(941), 383-388. http://dx.doi.org/10.1259/bjr/26829723

Zare, H., Bahreyni Toosi, M. T., Bayani, S., \& Esmaeeli, S. (2007). An evaluation of the organ dose received by cardiologists arising from angiography and angioplasty examinations in two educational hospitals in Mashhad. Iranian journal of medical physics, 3(11), 29-36.

\section{Copyrights}

Copyright for this article is retained by the author(s), with first publication rights granted to the journal.

This is an open-access article distributed under the terms and conditions of the Creative Commons Attribution license (http://creativecommons.org/licenses/by/3.0/). 